\title{
The impact of self-imagery on aspects of the self-concept in individuals with high levels of eating disorder cognitions
}

\section{Jodie Harlowe ${ }^{\mathrm{a}, *}$}

jodie.harlowe@nhs.net

Stephanie Farrar

Lusia Stopa

Hannah Turner

a'Clinical Psychology Programme, Psychology Academic Unit, University of Southampton, Shackleton Building (44a), Highfield Campus, Southampton, Hampshire, SO17 1BJ, UK

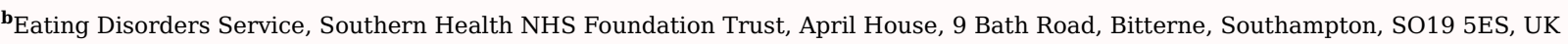

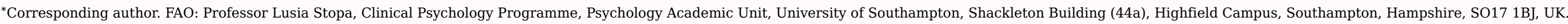

\section{Abstract}

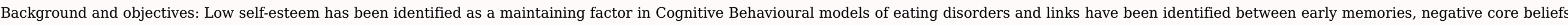

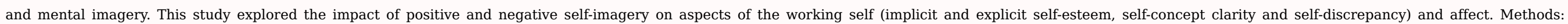

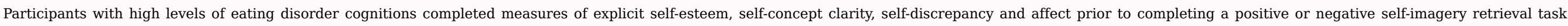

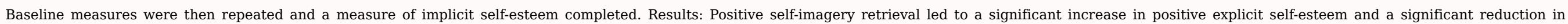

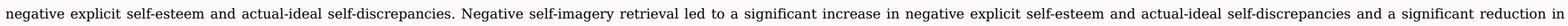

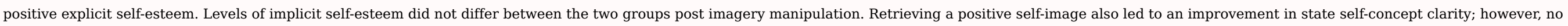

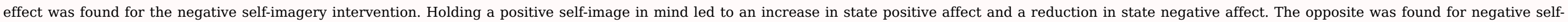

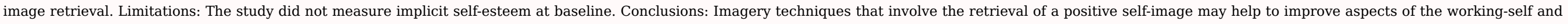
affect in those with eating difficulties.

\section{Introduction}

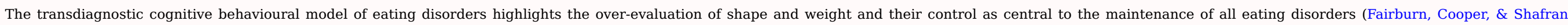

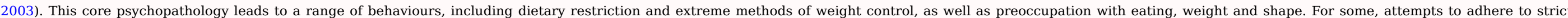

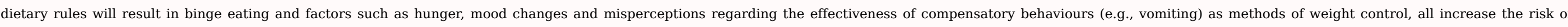

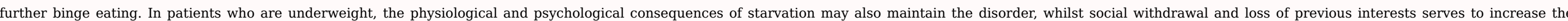

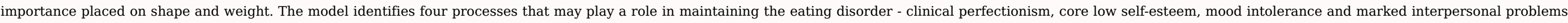

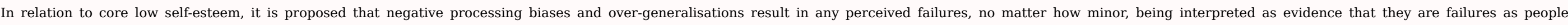
reaffirming their overall negative sense of self and maintaining eating disorder psychopathology (Fairburn et al., 2003).

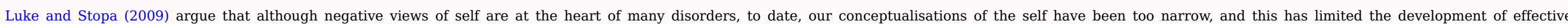

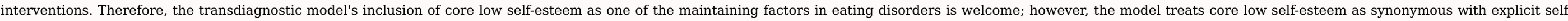

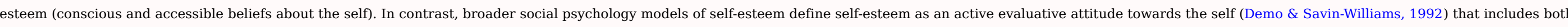

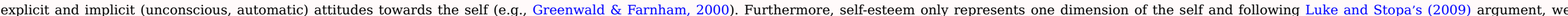




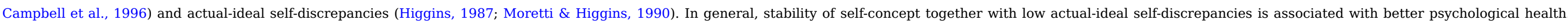
This is discussed in more detail below.

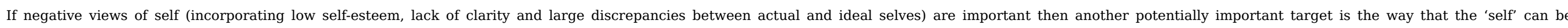

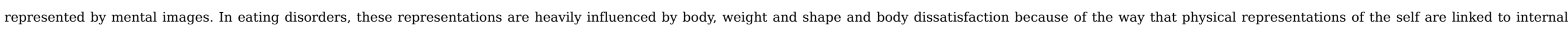

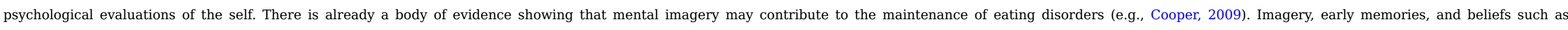

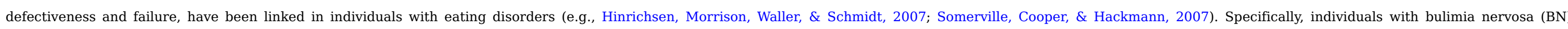

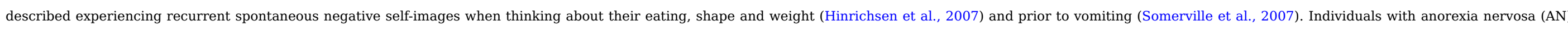

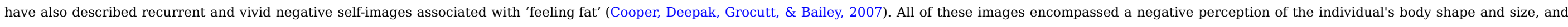

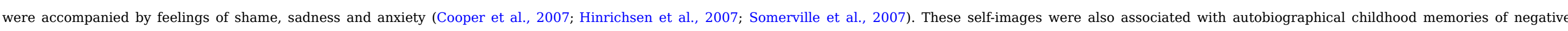

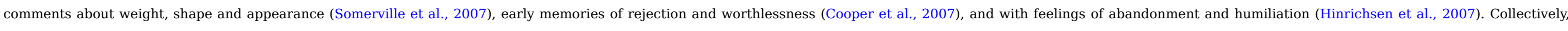
these findings support a role for negative self-images in the maintenance of disordered self-views and they may trigger behavioural symptoms (Hinrichsen et al., 2007).

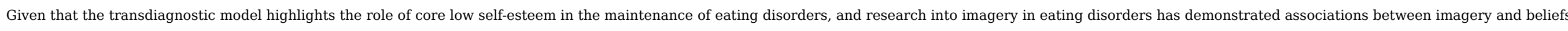

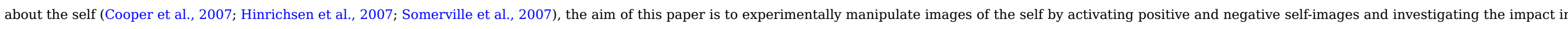

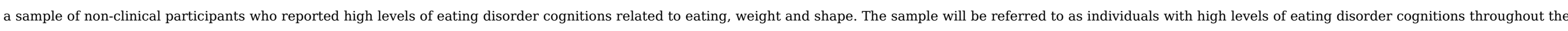

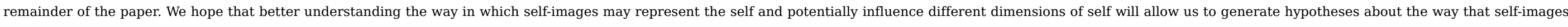
may maintain eating disorders, which can then be tested directly on clinical populations.

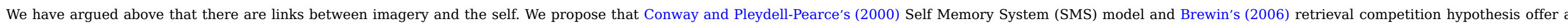

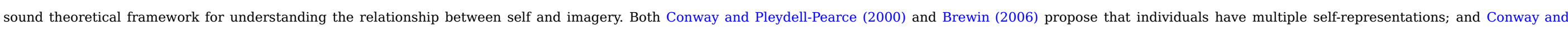

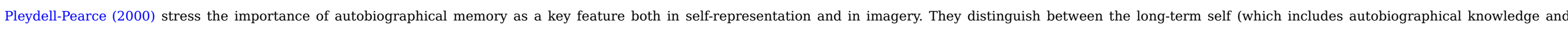

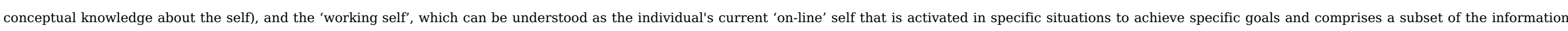

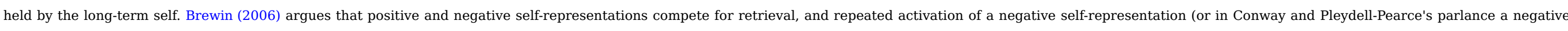

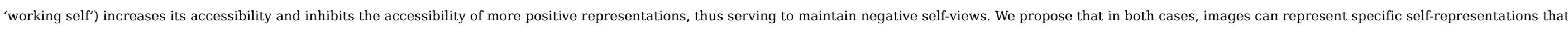
can be linked to the past through autobiographical memory and/or to the future by representing goals that the self aspires to.

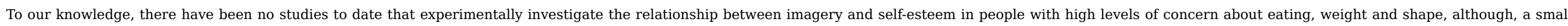

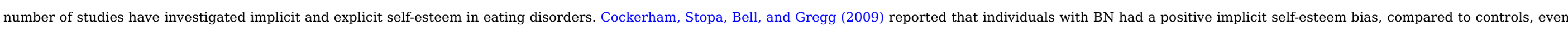

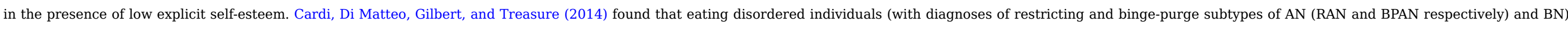

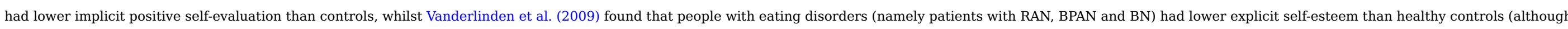

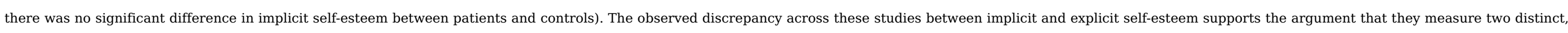

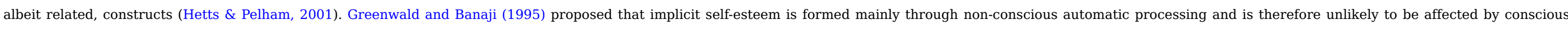

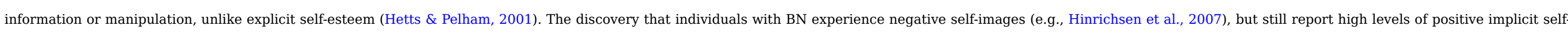

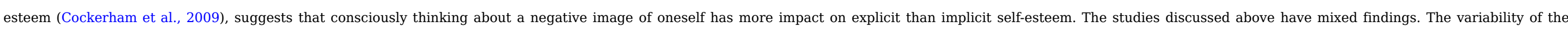

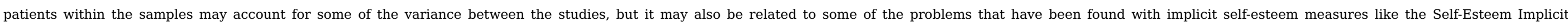
Association Test (SE-IAT; e.g., Rothermund \& Wentura, 2004; as discussed below).

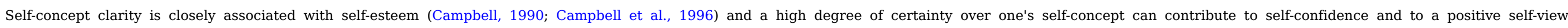

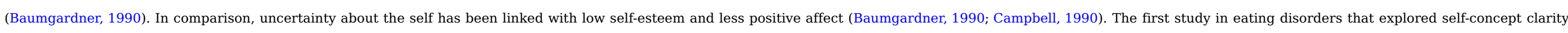




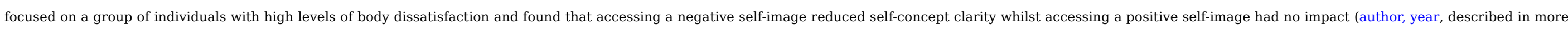

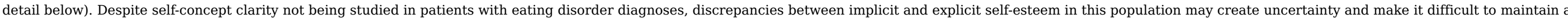
consistent and stable view of the self (Cockerham et al., 2009).

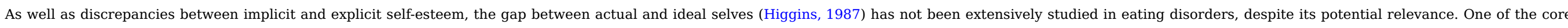

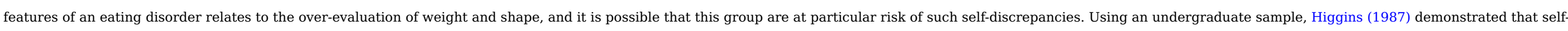

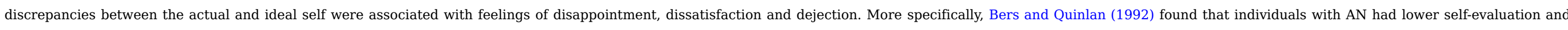

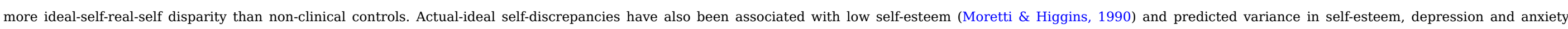

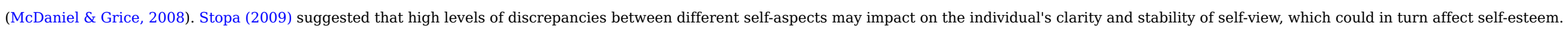

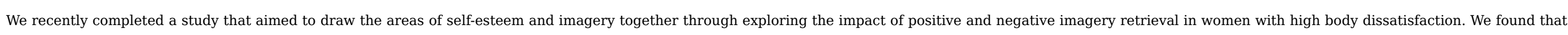

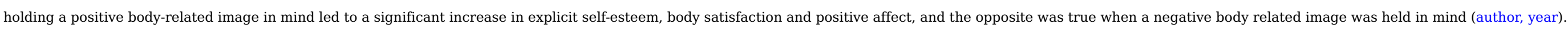

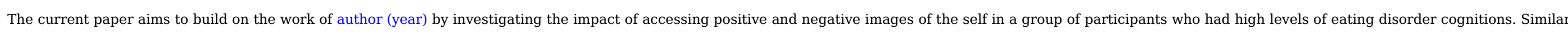

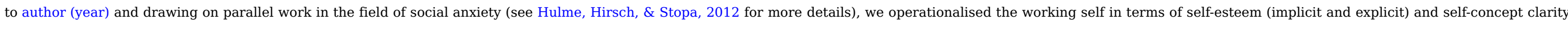

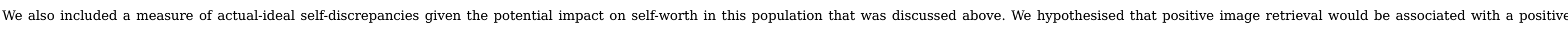

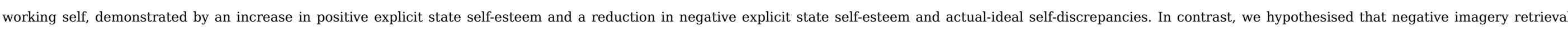

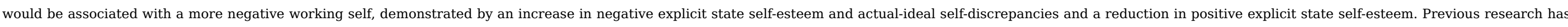

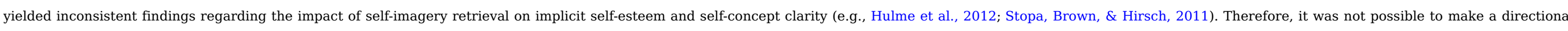

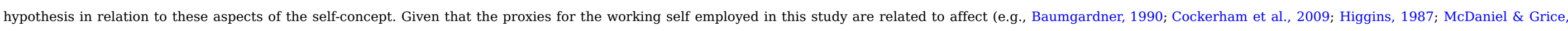
2008), a secondary hypothesis predicted that retrieving a positive self-image would increase positive affect and decrease negative affect, and retrieving a negative self-image would have the opposite effect.

\section{Material and methods \\ 2.1 Participants}

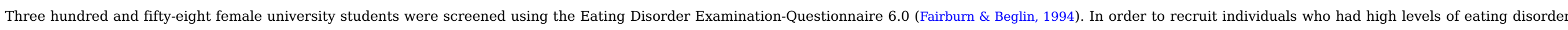

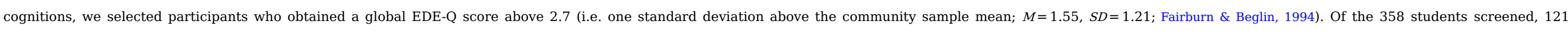

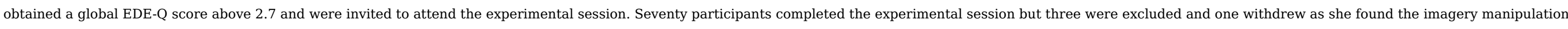

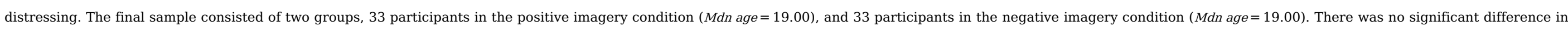
age of participants between the two conditions, $U=521.50, z=-0.31, p=.75$.

\subsection{Measures}

\subsubsection{Screening and descriptives}

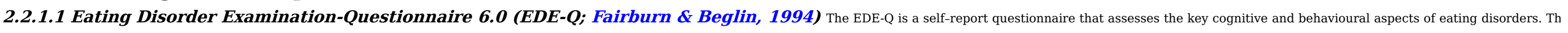

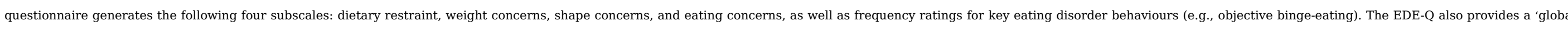

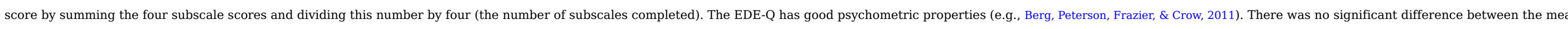
global EDE-Q scores of participants in the positive $(M=3.80, S D=0.60)$ and negative $(M=3.61, S D=0.56)$ imagery condition, $t(64)=1.33, p=.19$.

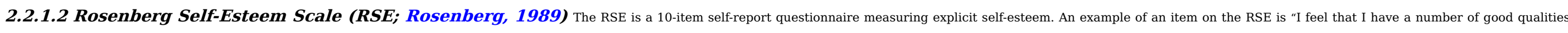

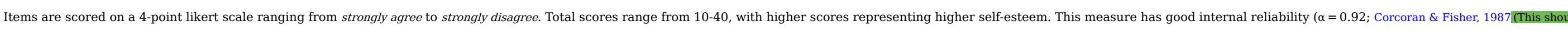
read Corcoran \& Fischer.)) and test-retest reliability over a six-month period (0.82; Murrell, Meeks, \& Walker, 1991). 


\subsubsection{Dependent variables}

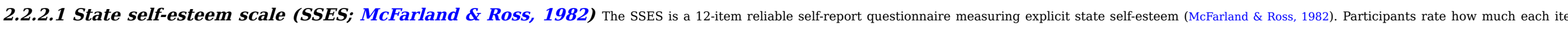

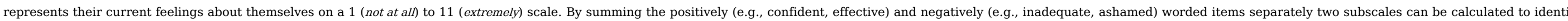
positive and negative self-esteem (McFarland \& Ross, 1982).

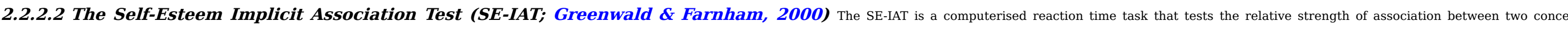

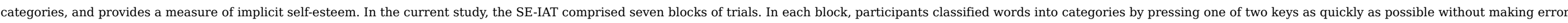

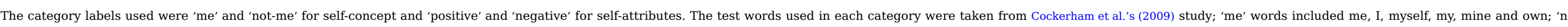

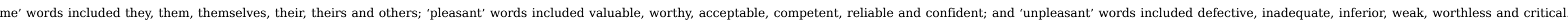
participants classified these words into a different category than those described above, the response was classified as an error

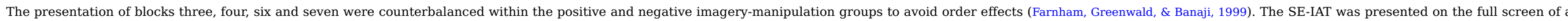

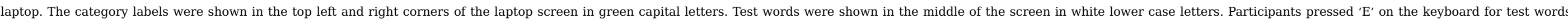

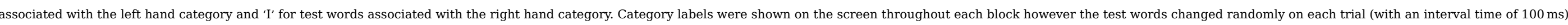
Errors were highlighted by a red cross appearing on the screen and a $200 \mathrm{~ms}$ pause, after which the next trial was presented without need for correction.

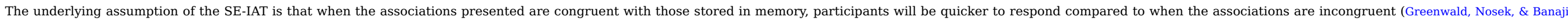

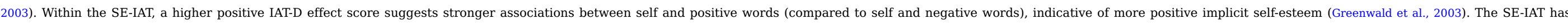

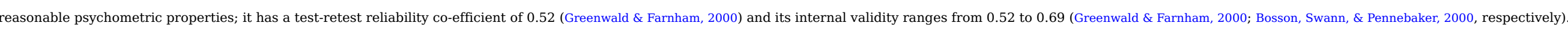

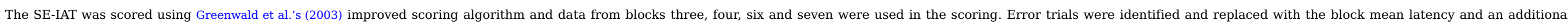

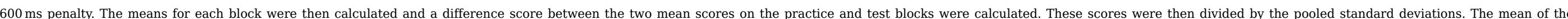
resulting scores were averaged to obtain the final score, the IAT-D effect. As no trials had either response latencies greater than 10,000 ms or over 10\% of trials in less than $300 \mathrm{~ms}$, all data were used in the analyses.

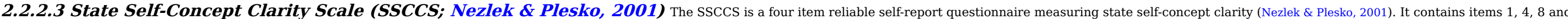

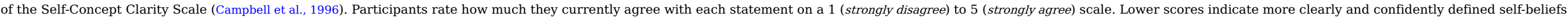

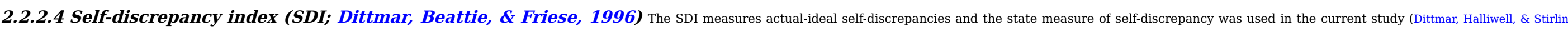

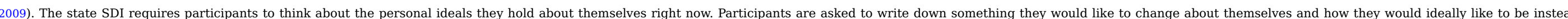

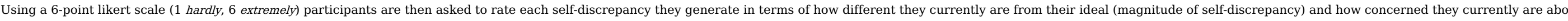

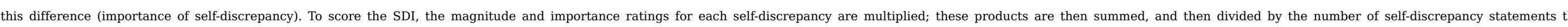

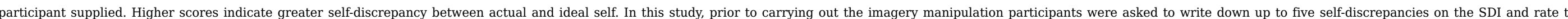
magnitude and importance of each one. Participants were asked to repeat the SDI magnitude and importance ratings following the imagery intervention.

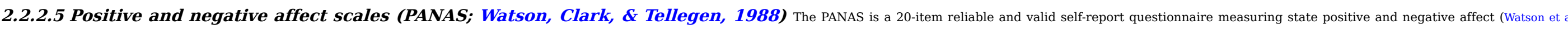

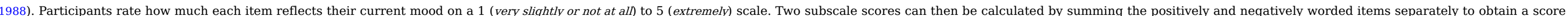
positive and negative mood.

\subsection{Experimental task: imagery manipulation}

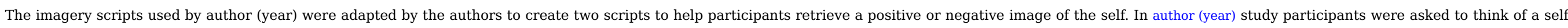

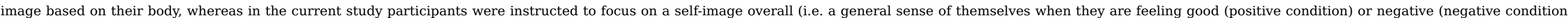

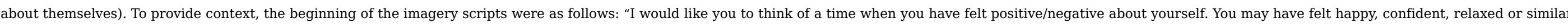

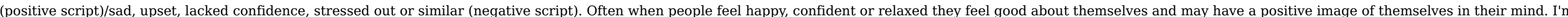




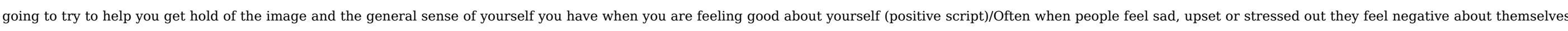

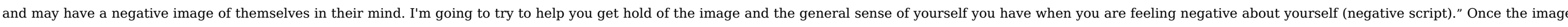

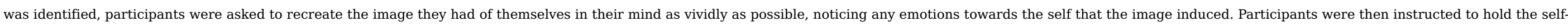
image in mind whilst they completed the measures immediately after the imagery manipulation.

\subsection{Manipulation checks}

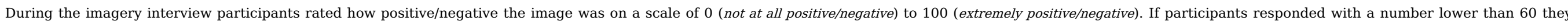

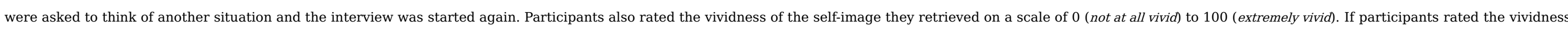

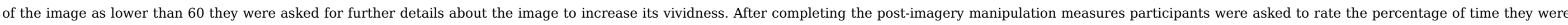
able to hold the self-image in mind whilst they completed the questionnaires and the SE-IAT on a scale of 0\% (not at all) to $100 \%$ (all the time).

\subsection{Procedure}

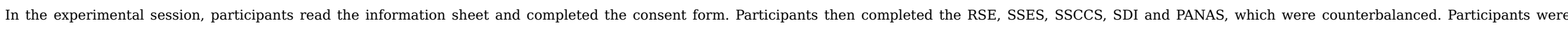

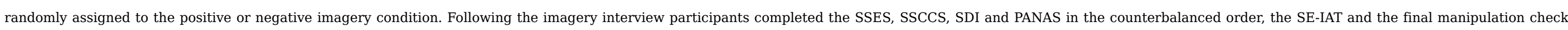
questions. The study received ethical approval from the local university.

\subsection{Data analysis}

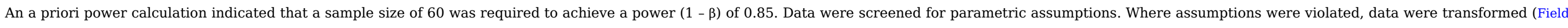

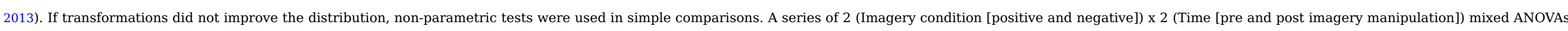

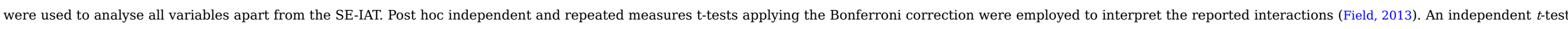
was used to analyse the data from the SE-IAT.

\section{Results}

\subsection{Descriptive statistics}

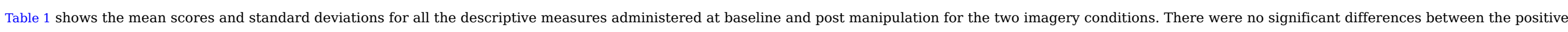
and negative imagery condition on any of the baseline measures ( $p$ values ranged from 0.20 to 0.89 ).

Table 1 Mean Scores and Standard Deviations (in parenthesis) for all of the Measures administered at Baseline and Post Manipulation for each Self-Imagery Condition.

alt-text: Table 1

Measure Positive Self-Imagery Condition

$$
(\mathrm{n}=33)
$$

Baseline

$17.27(4.18)$

RSE

State Positive Self-Esteem

State Negative Self-Esteem

State Self-Concept Clarity

State Self-Discrepancy

State Positive Affect

\begin{tabular}{|l|l|}
\hline $44.55(8.78)$ & $51.00(13.42)$ \\
\hline $22.33(8.47)$ & $15.06(9.10)$ \\
\hline $13.79(3.83)$ & $12.27(4.75)$ \\
\hline $18.78(5.24)$ & $14.81(7.56)$ \\
\hline
\end{tabular}

$27.64(8.20)$
32.85 (10.16)
Negative Self-Imagery Condition

$(n=33)$

Post

Baseline

Post

$16.09(4.13)$

41.61 (9.71)

$21.70(8.29)$

$14.21(3.14)$

19.68 (3.38)

$27.91(7.64)$
31.39 (12.68)

33.09 (8.58)

14.48 (3.06)

26.73 (5.27)

22.18 (8.49) 


\begin{tabular}{|l|l|l|l|l|l|l|l|l}
\hline State Negative Affect & $17.42(6.26)$ & $15.58(7.20)$ & $17.06(5.82)$ & $0.08(0.73)$ & $(7.86)$ \\
\hline IAT D Effect Score & & $-0.03(0.60)$
\end{tabular}

Notes. Rosenberg Self-Esteem Scale (RSE; Rosenberg, 1989), Implicit Association Test (IAT; Greenwald \& Farnham, 2000).

\subsection{Imagery manipulation checks}

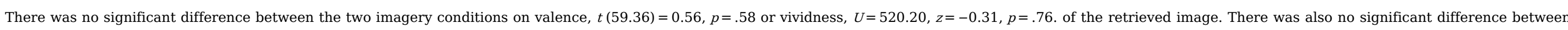

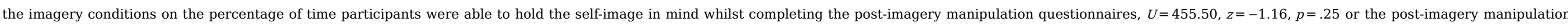

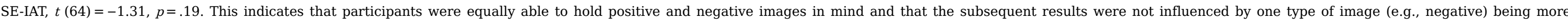
accessible than the other

\subsection{Self-concept measures}

\subsubsection{Explicit state positive self-esteem}

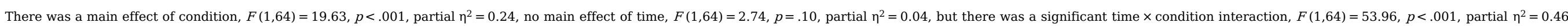
Positive self-esteem significantly increased after positive imagery retrieval, $t(32)=-3.59, p<.001, r=0.54$, and significantly decreased after negative imagery retrieval, $t(32)=7.40, p<.001, r=0.80$

\subsubsection{Explicit state negative self-esteem}

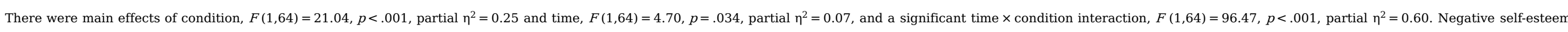
significantly increased after negative imagery retrieval, $t(32)=-8.86, p<.001, r=0.84$, and significantly decreased after positive imagery retrieval, $t(32)=5.20, p<.001, r=0.68$.

\subsubsection{Implicit self-esteem}

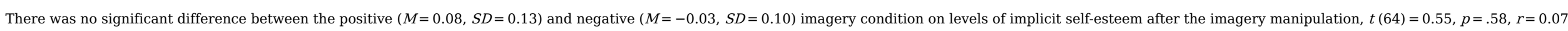

\subsubsection{State self-concept clarity}

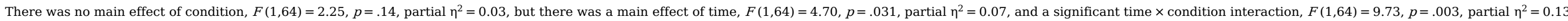

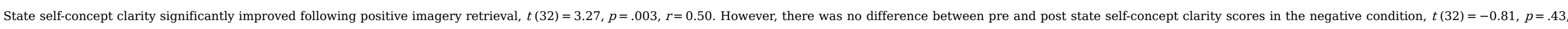
$r=0.14$

\subsubsection{State self-discrepancies}

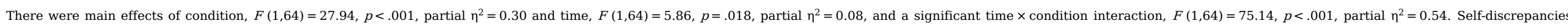
significantly decreased following positive imagery retrieval, $t(32)=3.47, p<.001, r=0.51$ and significantly increased following negative imagery retrieval, $t(32)=-12.82, p<.001, r=0.91$.

\subsubsection{Summary of the impact of positive and negative imagery on self-variables}

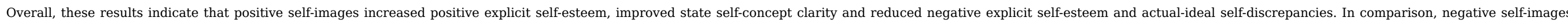
increased negative self-esteem and actual-ideal self-discrepancies and reduced positive explicit self-esteem. Negative self-images had no impact on self-concept clarity.

\subsection{Affect measures}

\subsubsection{State positive affect}

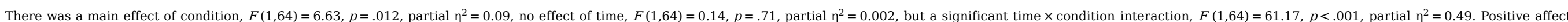




\subsubsection{State negative affect}

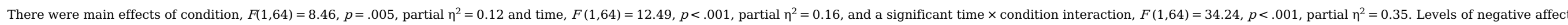
significantly increased following negative imagery retrieval, $t(32)=7.51, p<.001, r=0.80$, and decreased following positive imagery retrieval, $t(32)=-2.68, p=.011, r=0.43$

\subsubsection{Summary of the impact of positive and negative images on affect}

Overall, the results of the state affect measures demonstrate that positive images increase positive and decrease negative affect, whereas negative images do the opposite (increase negative and decrease positive affect).

\section{Discussion}

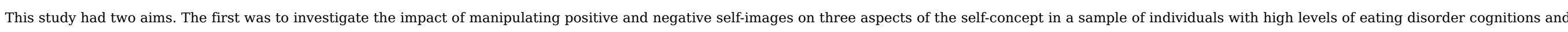

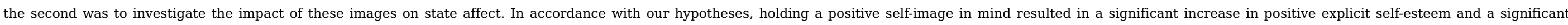

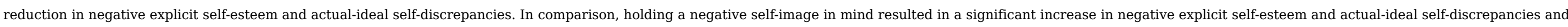

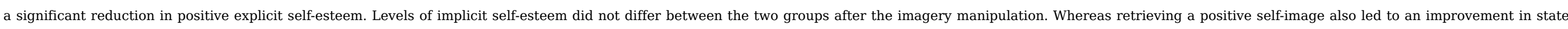

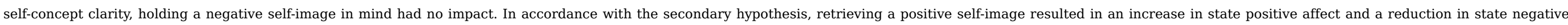
affect. The opposite was found when a negative self-image was retrieved.

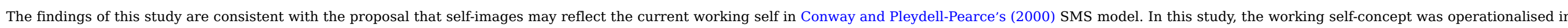

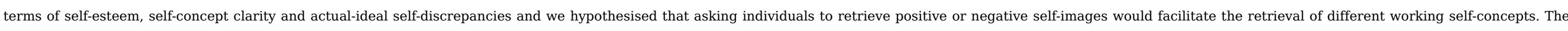
results of the current study, together with previous research on other participant groups, are consistent with this hypothesis (Hulme et al., 2012).

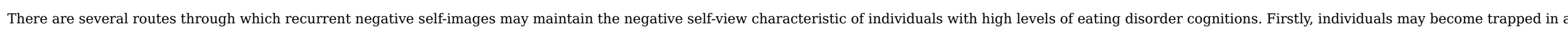

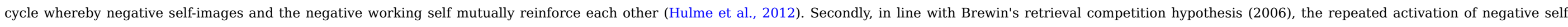

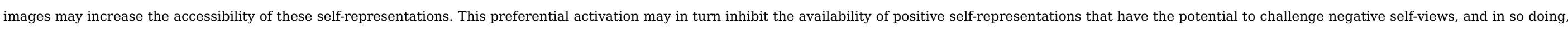
improve a person's sense of self-worth (author, year).

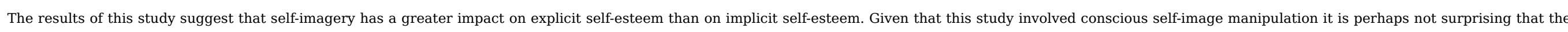

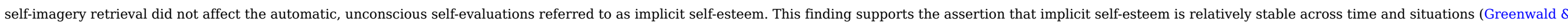

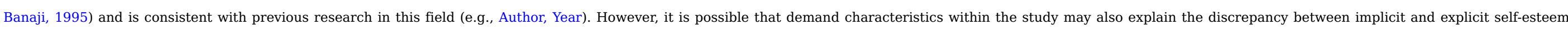

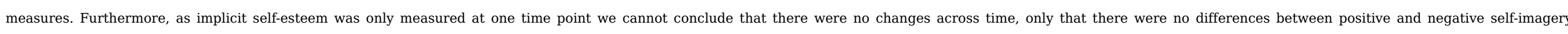

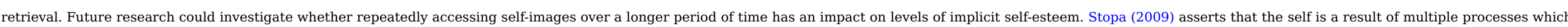

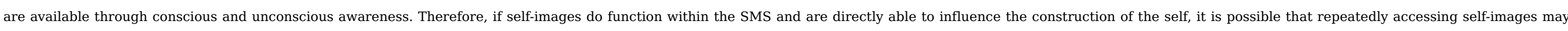
influence implicit as well as explicit self-esteem.

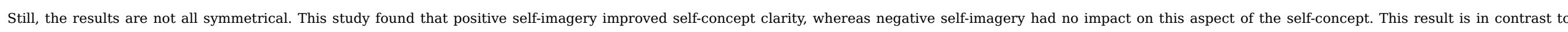

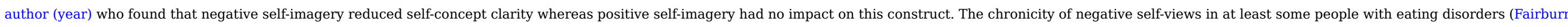

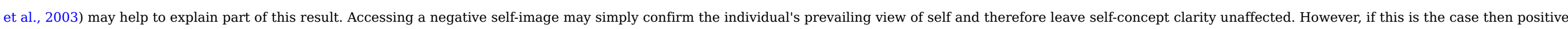

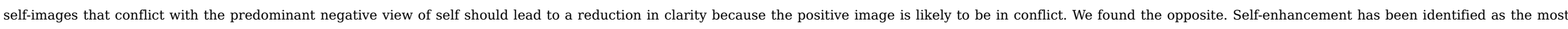

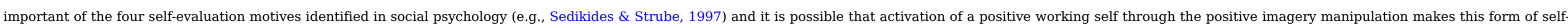
enhancement more salient, and thus improves clarity about the self.

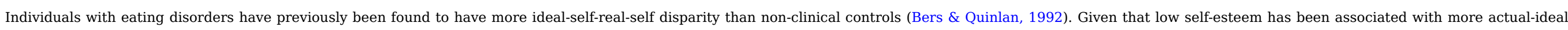




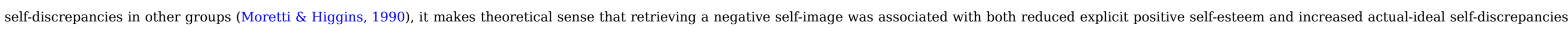

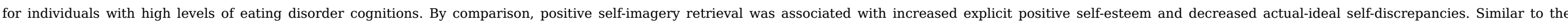

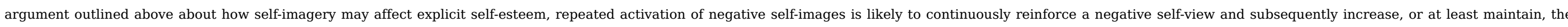

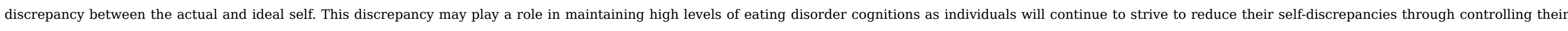
eating, weight and shape.

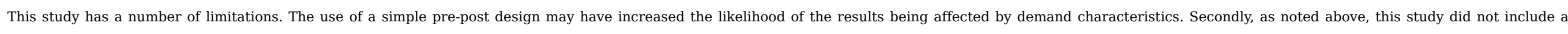

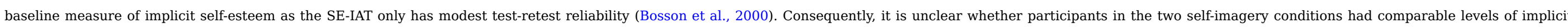

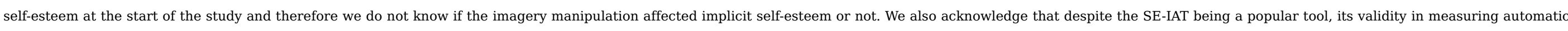

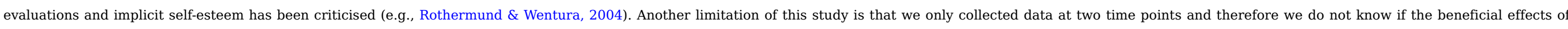

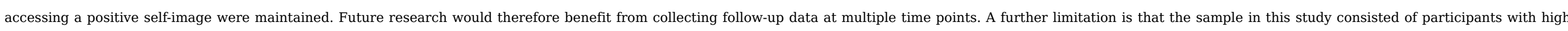

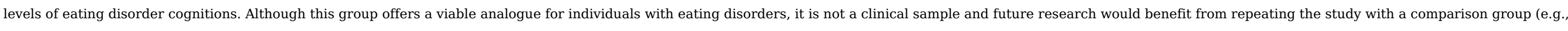

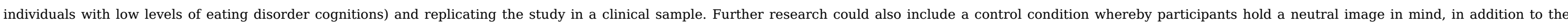

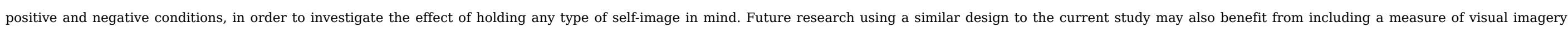
vividness, such as the Vividness of Visual Imagery Questionnaire (VVIQ; Marks, 1973), to assess whether the vividness of participants' visual imagery affects the impact of the imagery manipulation.

\section{Conclusions}

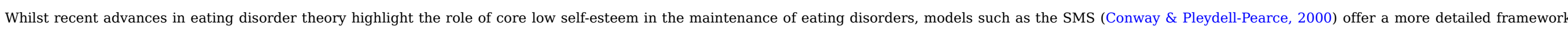

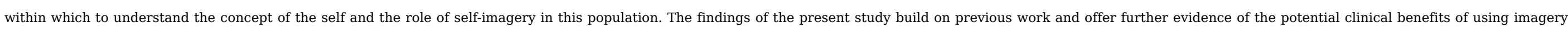
related techniques, such as positive imagery retrieval, when working with individuals with high levels of eating disorder cognitions.

\section{Acknowledgements, declaration of interest, and role of funding organisations}

None to declare.

\section{Appendix A. Supplementary data}

Supplementary data related to this article can be found at https://doi.org/10.1016/j.jbtep.2018.05.002

\section{References}

Author, (year).

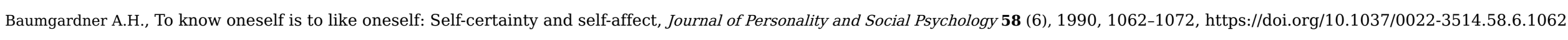

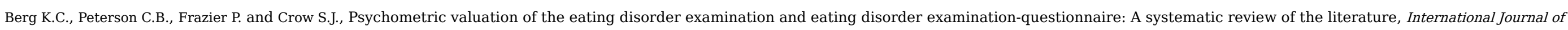
Eating Disorders 45, 2011, 428-438, https://doi.org/10.1002/eat.20931.

Bers S.A. and Quinlan D.M., Perceived-competence deficit in anorexia nervosa, Journal of Abnormal Psychology 101 (3), 1992, 423-431, https://doi.org/10.1037/0021-843X.101.3.423.

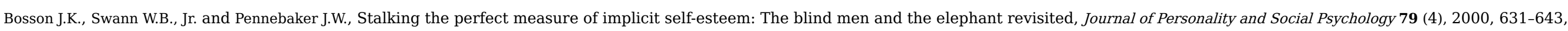

https://doi.org/10.1037/0022-3514.79.4.631.

Brewin C.R., Understanding cognitive behaviour therapy: A retrieval competition account, Behaviour Research and Therapy 44 (6), 2006, 765-784, https://doi.org/10.1016/j.brat.2006.02.005.

Campbell J.D., Self-esteem and clarity of the self-concept, Journal of Personality and Social Psychology 59 (3), 1990, 538-549, https://doi.org/10.1037/0022-3514.59.3.538. 


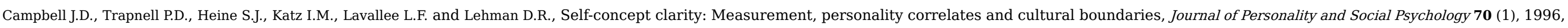

141-156, https://doi.org/10.1037/0022-3514.70.1.141.

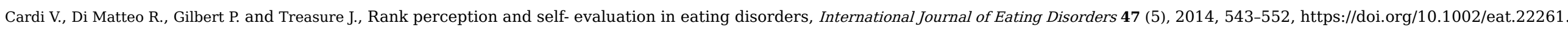

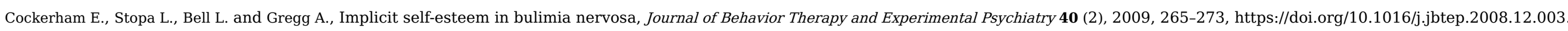

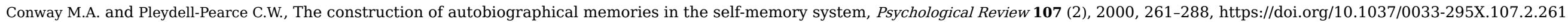

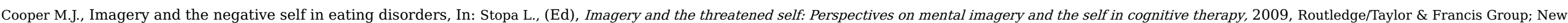
York, NY US, 181-205.

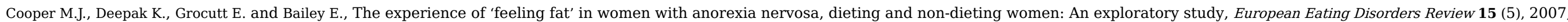
366-372, https://doi.org/10.1002/erv.785.

Corcoran K. and Fisher(This should be Fischer) J., Measures for clinical practice: A new sourcebook, 1987, The Free Press; New York, NY US.

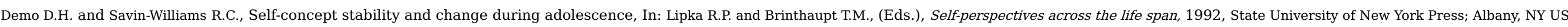

116-150.

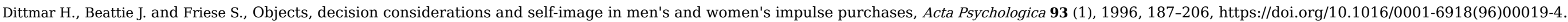

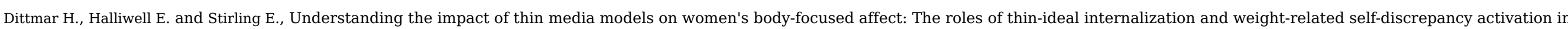

experimental exposure effects, Journal of Social and Clinical Psychology 28 (1), 2009, 43-72, https://doi.org/10.1521/jscp.2009.28.1.43.

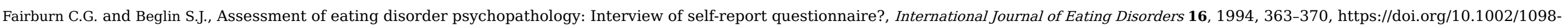

108X(199412)16:4<363::AID-EAT2260160405>3.0.CO.

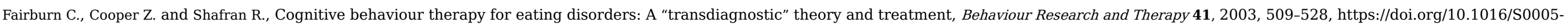
7967(02)00088-8.

Farnham S.D., Greenwald A.G. and Banaji M.R., Implicit self-esteem, In: Abrams D. and Hogg M.A., (Eds.), Social identity and social cognition, 1999, Blackwell Publishing; Malden, England, 230-248.

Field A., Discovering statistics using IBM SPSS statistics, 4th ed., 2013, Sage Publications Inc; Thousand Oaks, CA US.

Greenwald A.G. and Banaji M.R., Implicit social cognition: Attitudes, self-esteem and stereotypes, Psychological Review 102 (1), 1995, 4-27, https://doi.org/10.1037/0033-295X.102.1.4.

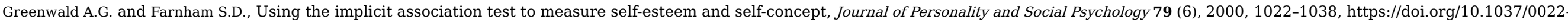
3514.79.6.1022.

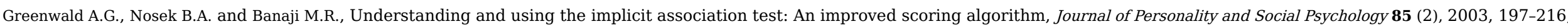
https://doi.org/10.1037/0022-3514.85.2.197.

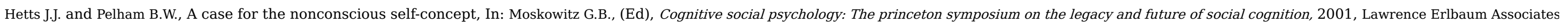
Publishers; Mahwah, NJ US, 105-123.

Higgins E.T., Self-discrepancy: A theory relating self and affect, Psychological Review 94 (3), 1987, 319-340, https://doi.org/10.1037/0033-295X.94.3.319.

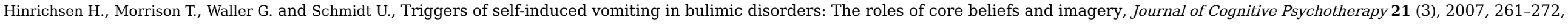
https://doi.org/10.1891/088983907781494528. 
Hulme N., Hirsch C. and Stopa L., Images of the self and self-esteem: Do positive self-images improve self-esteem in social anxiety?, Cognitive Behaviour Therapy 41 (2), 2012, 163-173, https://doi.org/10.1080/16506073.2012.664557.

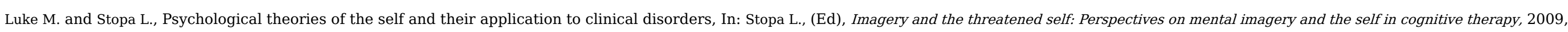
Routledge/Taylor \& Francis Group; New York, NY US, 15-64.

McDaniel B.L. and Grice J.W., Predicting psychological well-being from self- discrepancies: A comparison of idiographic and nomothetic measures, Self and Identity 7 (3), 2008, 243-261, https://doi.org/10.1080/15298860701438364.

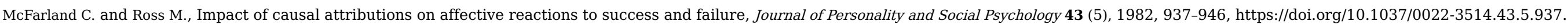

Moretti M.M. and Higgins E.T., Relating self-discrepancy to self-esteem: The contribution of discrepancy beyond actual-self ratings, Journal of Experimental Social Psychology 26 (2), 1990, 108-123,

https://doi.org/10.1016/0022-1031(90)90071-S.

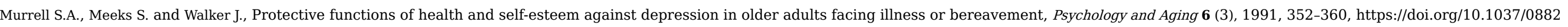
7974.6.3.352.

Nezlek J.B. and Plesko R.M., Day-to-day relationships among self-concept clarity, self-esteem, daily events, and mood, Personality and Social Psychology Bulletin 27 (2), 2001, 201-211,

https://doi.org/10.1177/0146167201272006

Rosenberg M., Society and the adolescent self-image, (rev. ed.)1989, Wesleyan University Press; Middletown, CT England.

Rothermund K. and Wentura D., Underlying processes in the implicit association test: Dissociating salience from associations, Journal of Experimental Psychology: General 133 (2), 2004, 139-165, https://doi.org/10.1037/0096-3445.133.2.139.

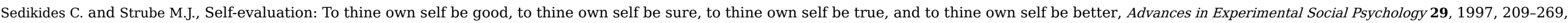
https://doi.org/10.1016/S0065-2601(08)60018-0.

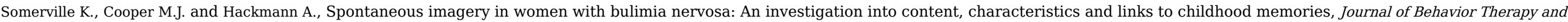
Experimental Psychiatry 38 (4), 2007, 435-446, https://doi.org/10.1016/j.jbtep.2007.09.003.

Stopa L., Imagery and the threatened self: Perspectives on mental imagery and the self in cognitive therapy, 2009, Routledge/Taylor \& Francis Group; New York, NY US.

Stopa L., Brown M.A. and Hirsch C.R., Seeing myself and knowing myself: Images and self-representation in social anxiety, Unpublished manuscript2011.

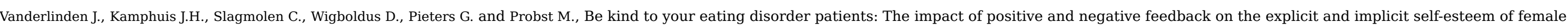
patients with eating disorders, Eating and Weight Disorders-Studies on Anorexia, Bulimia and Obesity 14 (4), 2009, 237-242, https://doi.org/10.1007/BF03325124.

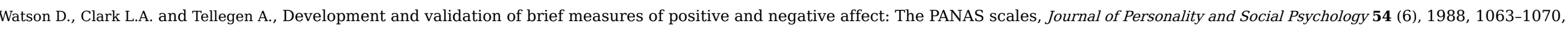
https://doi.org/10.1037/0022-3514.54.6.1063.

\section{Appendix A. Supplementary data}

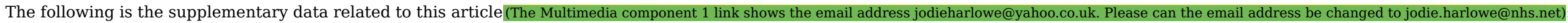




\section{Highlights}

- Impact of positive and negative self-imagery on the working-self and mood.

- Positive self-imagery improved positive self-esteem and self-concept clarity.

- Positive self-imagery reduced actual-ideal self-discrepancies and improved mood.

- Negative self-imagery had a negative impact on the self-concept and affect.

- Positive imagery retrieval may help to improve self-concept in this group.

\section{Queries and Answers}

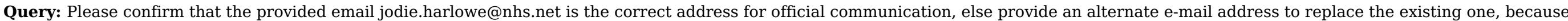
private e-mail addresses should not be used in articles as the address for communication.

Answer: jodie.harlowe@nhs.net is the correct email address to be used for official communication.

Query: The citation "Corcoran \& Fischer, 1987; Rothermund and Wentura, 2001" have been changed to match the author name/date in the reference list. Please check.

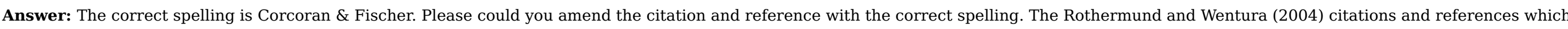
you have amended are correct.

Query: Ref. Marks, 1973 is cited in the text but not provided in the reference list. Please provide it/them in the reference list or delete these citations from the text.

Answer: Marks, D. F. (1973). Visual imagery differences in the recall of pictures. British Journal of Psychology, 64(1), 17-24. doi: 10.1111/j.2044-8295.1973.tb01322.x

Query: Please provide full details for ref. Author, (year).

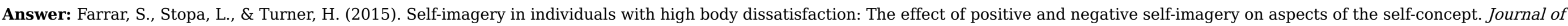
Behavior Therapy and Experimental Psychiatry, 46, 8-13. doi: 10.1016/j.jbtep.2014.07.011

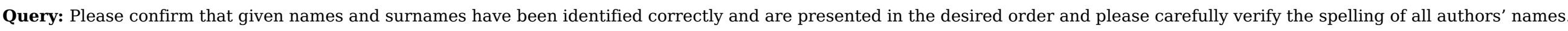

Answer: Yes, these are all correct.

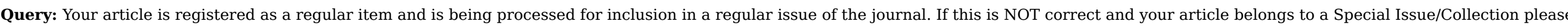
contact b.mahadevan@elsevier.com immediately prior to returning your corrections.

Answer: Yes, this is correct. 